\title{
Role of Hormonal and Reproductive Factors in the Etiology and Treatment of Uterine Leiomyoma
}

\author{
CHERYL L. WALKeR \\ The University of Texas M.D. Anderson Cancer Center, Department of Carcinogenesis, \\ Science Park-Research Division, Smithville, Texas 78957
}

\begin{abstract}
Uterine leiomyomas are the most common gynecologic neoplasm in reproductive-age women. While it is clear that hormonal factors play a prominent role in this disease, how steroid hormones contribute to disease etiology or may be utilized as targets for intervention are currently areas of active scientific investigation. To study the impact of hormones on uterine leiomyomas, the Eker rat has been developed as an in vivo/in vitro animal model system for these tumors. Spontaneous leiomyomas arise in intact Eker rats with a high frequency and leiomyoma-derived cell lines from these animals maintain the biochemical and physiological characteristics of the tumors from which they were obtained. Using this animal model system, it has been established that tumor development is absolutely dependent on steroid hormones and that sensitivity/responsiveness to estrogen is enhanced in tumors and tumor-derived cell lines. Modulation of hormonal milieu, such as that which naturally occurs during pregnancy, can effectively inhibit tumor development. The hormone responsiveness of these tumors makes them good candidates for hormonal therapy. Selective estrogen receptor modulators (SERMs) tamoxifen and raloxifene hold promise as potential therapeutic agents for this disease. SERMs inhibit proliferation of leiomyoma-derived cell lines in vitro, repress the growth of these lines in nude mice, and, when administered over a 2- to 4-month course of treatment to Eker rats, reduce tumor incidence by more than $50 \%$. In addition to endogenous hormones, xenoestrogens in our environment (e.g., phytoestrogens, organochlorine pesticides, pharmacologic compounds) are of potential concern with regards to their impact on this disease. These environmental estrogens have been shown to promote the growth of leiomyoma cells in vitro and in vivo. Further elucidation of the role of these and other hormonal and reproductive factors in the development of uterine leiomyoma will be invaluable for increasing our understanding of the etiology of this disease and developing new therapeutic strategies to help to reduce the negative impact of uterine leiomyomas on women's health.
\end{abstract}

\section{Introduction}

Uterine leiomyomas, commonly referred to as "fibroids," are benign tumors arising from the myometrial compartment of the uterus. They are typically well differentiated, have a relatively low mitotic index, and retain their smooth muscle phenotype. Uterine leiomyomas are the most common gynecologic neoplasm, occurring with a remarkable frequency in more than $70 \%$ of reproductive age 
women (Cramer and Patel, 1990). Tumors can become quite large and are usually multiple. When symptomatic, they are associated with infertility, menorrhagia, and spontaneous abortion and are the leading indication for hysterectomy in premenopausal women (Buttram and Reiter, 1981).

\section{The Eker Rat Model for Uterine Leiomyoma}

The Eker rat has been extensively characterized as an in vitro/in vivo animal model for uterine leiomyoma (Everitt et al., 1995; Howe et al., 1995a). Female Eker rats carrying a germline mutation in the tuberous sclerosis 2 (Tsc-2) tumor suppressor gene develop uterine leiomyomas by 12-16 months of age with a frequency of $\approx 65 \%$ (Everitt et al., 1995). The predisposing genetic alteration in these animals is an insertion of an endogenous retrovirus between exons 30 and 31 of the Tsc- 2 gene, which inactivates the tumor suppressor protein encoded by this gene (Yeung et al., 1994; Kobayashi et al., 1995). The uterus is a site of high expression of tuberin, the product of the Tsc-2 gene, and tumors that arise in heterozygous animals show loss of tuberin function. At the DNA level, loss of heterozygosity $(\mathrm{LOH})$ at the Tsc-2 locus is commonly observed in these tumors, with loss of tuberin function occurring by several mechanisms, including loss of chromosome 10 on which the wild-type Tsc-2 gene is located (either monosomy or chromosome nondisjunction with retention of two copies of chromosome 10 containing the mutant allele), gene silencing, and point mutations (Yeung et al., 1995).

Uterine leiomyomas that arise in the Eker rat share many phenotypic characteristics with their cognate human disease. Tumors occur spontaneously with a high frequency in intact cycling females. They are often multiple and resemble human leiomyomas histologically (Everitt et al., 1995). Eker rat leiomyomas are benign and their malignant counterparts, uterine leiomyosarcomas, are rarely seen. The similarity in pathogenesis of uterine leiomyoma in Eker rats and women has made these animals useful as a model system to experimentally address questions related to the role of hormones in tumor development and hormonal and reproductive factors that can modulate or prevent the development of this disease.

\section{Eker Leiomyoma Tumor-derived Cell Lines}

Several cell lines have been developed from Eker rat uterine leiomyomas (Howe et al., 1995a). These cell lines have been given the designation ELT (for Eker leiomyoma tumor-derived) and, to date, five such lines have been established and characterized (Table I). All five cell lines are positive for expression of smooth muscle $\alpha$ and $\gamma$ actins and desmin by northern analysis and immunocytochemistry. As shown in Table I, the cell lines vary with respect to steroid 
TABLE I

Characteristics of ELT Cell Lines

\begin{tabular}{llllll}
\hline & ELT-3 & ELT-4 & ELT-6 & ELT-9 & ELT-10 \\
\hline $\begin{array}{l}\text { Smooth } \\
\text { muscle actin }\end{array}$ & Positive & Positive & Positive & Positive & Positive \\
$\begin{array}{l}\text { Desmin } \\
\text { Estrogen }\end{array}$ & Positive & Positive & Positive & Positive & Positive \\
receptor & Positive & Positive & Negative & Positive & Positive \\
$\begin{array}{l}\text { Progesterone } \\
\text { receptor }\end{array}$ & $\begin{array}{l}\text { Positive } \\
(\mathrm{Kd}=1.3 \mathrm{nM})\end{array}$ & Positive & Negative & Positive & Positive \\
$\begin{array}{l}\text { Tumorigenicity } \\
\text { in nude mice }\end{array}$ & Tumorigenic & $\begin{array}{l}\text { Nontumori- } \\
\text { genic }\end{array}$ & $\begin{array}{l}\text { Nontumori- } \\
\text { genic }\end{array}$ & $\begin{array}{l}\text { Nontumori- } \\
\text { genic }\end{array}$ & $\begin{array}{l}\text { Nontumori- } \\
\text { genic }\end{array}$ \\
\hline
\end{tabular}

hormone receptor expression and tumorigenicity, although, in general, these lines continue to express both estrogen and progesterone receptors in culture and are nontumorigenic in nude mice.

\section{Hormone-responsive Phenotype of Uterine Leiomyoma}

A substantial body of evidence from human clinical and epidemiological observations and experimental data obtained using the Eker rat model point to the hormone responsiveness of uterine leiomyomas. These tumors are most symptomatic in pre- and perimenopausal women and often change dramatically in size during pregnancy (Rossi and Diamond, 1992; Strobelt et al., 1994). The indication for hysterectomy due to symptomatic fibroids reaches a maximum incidence at 45 years of age, then declines dramatically, coinciding with the onset of menopause (Cramer, 1992). Uterine leiomyomas express estrogen receptors (ERs) and progesterone receptors (PRs) at levels that have been reported to be the same or higher than normal myometrium (Rein and Nowak, 1992; Brandon et al., 1993,1995; Viville et al., 1997; Englund et al., 1998; Nisolle et al., 1999). Treatment with gonadotropin-releasing hormone $(\mathrm{GnRH})$ agonists is a commonly used adjuvant therapy for these tumors. The hypoestrogenic state induced by these compounds effectively shrinks tumor volume (Andreyko et al., 1987; Adamson, 1992). However, the inhibition of steroid hormone production by GnRH agonists can cause a significant loss of bone mineral density (Dawood et al., 1989), limiting the course of treatment to less than 6 months. Moreover, cessation of therapy results in regrowth of these tumors, often rapidly (Friedman et al., 1990).

In the Eker rat model, the dependence of these tumors on ovarian hormones has been demonstrated unequivocally. Ovariectomy at 4 months of age virtually 
ablates tumor development, whereas animals receiving sham surgeries have a tumor incidence at 16 months of $\approx 65 \%$ (Walker et al., 2000). Similarly, analysis of cell proliferation in normal myometrium and leiomyomas of Eker rats suggests that these tumors have an enhanced responsiveness to the mitogenic effects of estrogens (Burroughs et al., 2000). As shown in Figure 1, in young animals, myometrial cell proliferation correlates well with estrogen levels, being highest when estrogen levels peak during proestrus. As the animal matures, however, myometrial cells become refractory to the mitogenic stimulus of estrogen. This phenomenon appears to be specific for mesenchymal cells of the uterus. While both smooth muscle myometrial cells and endometrial stomal cells become refractory to the proliferative effects of estrogen with age, this is not observed for either luminal or glandular epithelial cells of the endometrium (Burroughs et al., 2000). In contrast, leiomyomas exhibit a significantly elevated proliferative index relative to age-matched normal myometrium, suggesting an enhanced sensitivity to the mitogenic effects of steroid hormones in these tumors (Burroughs et al., 2000). This conclusion is supported by data using human leiomyoma explants, which demonstrated that tumor cells displayed an enhanced sensitivity to estro-

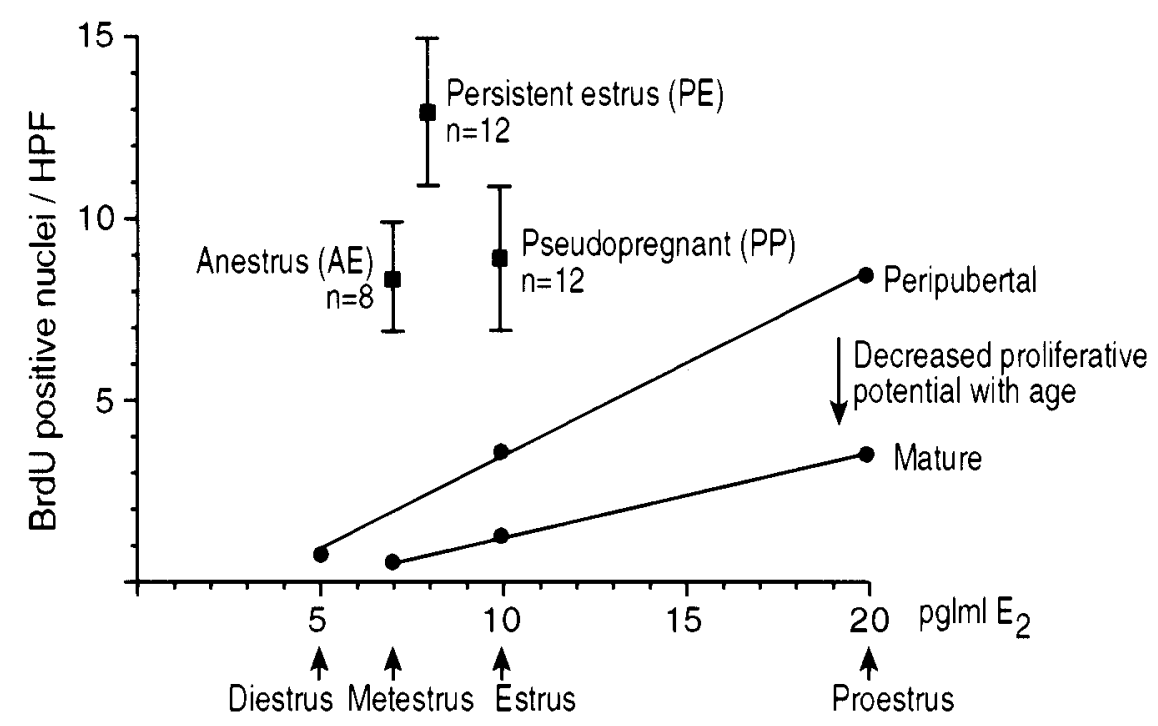

FIG. 1. Cell proliferation in normal myometrium and leiomyomas. Cell proliferation was measured by quantitation of BrdU incorporation into DNA followed by identification of BrdUpositive nuclei by immunohistochemistry using antibodies directed against BrdU. Cell proliferation positively correlated with serum estrogen levels but an overall decrease in the mitogenic response to estrogen occurred in the myometrium with age. Tumors exhibited an increased sensitivity/responsiveness to estrogen relative to normal myometrium. 
gen at the transcriptional level, relative to normal myometrial cells (Andersen et al., 1995).

It is important to appreciate that there are species-specific differences in how levels of estrogen and progesterone change during the menstrual cycle of women and the estrus cycle of rodents. In women, estrogen levels exhibit two peaks: one during late-follicular/proliferative phase of the cycle and a second, broader surge during the luteal/secretory phase. In contrast, progesterone levels are elevated only during the luteal phase of the cycle (Figure 2). Thus, while the luteal phase of the menstrual cycle is often considered to be "progesterone driven," it is important to appreciate that total exposure to estrogen during this phase of the cycle is higher or equal to that of the follicular phase in cycling women. In rodents, circulating estrogen levels peak in proestrus and drop precipitously during estrus following ovulation. Although estrogen levels begin to rise again during diestrus, these levels remain very much attenuated relative to the surge in estrogen that occurs during proestrus. In contrast, progesterone levels show a dramatic bimodal pattern. Peaks in progesterone levels occur during both early proestrus and metestrus (Figure 2), so that significant exposure to progesterone occurs in both early and late phases of the cycle. Therefore, in women, highest coincident estrogen and progesterone exposure occurs during the luteal phase of the cycle, whereas, in rodents, the highest coincident estrogen and progesterone levels occur in proestrus.

The biology of leiomyomas in rats and humans reflects this difference in physiology. For example, in leiomyomas, both cell proliferation and apoptosis vary as a function of the menstrual/estrus cycle. In humans, although the data are limited, leiomyomas appear to be most proliferative during the luteal phase of the cycle (Kawaguchi et al., 1989). Subsequent reports tend to support this earlier data (Nisolle et al., 1999; Wu and Somlo, 2000), although in one of these studies, the difference between proliferation occurring in the two phases did not reach statistical significance (Nisolle et al., 1999). In the Eker rat, empirical data have recently been obtained that demonstrate that cell proliferation in these tumors is maximal during proestrus, where hormone levels correspond to the high estrogen and progesterone levels that occur during the luteal phase in women. Conversely, in the normal myometrium, apoptosis is maximal during estrus, when steroid hormones are approaching their nadir. In addition, leiomyomas in the Eker rat model have been demonstrated to have a defective apoptotic program, relative to age-matched normal myometrium (Burroughs et al., 2000). Human data on apoptotic rates in leiomyoma are extremely limited, although there is some suggestion of such a defect from clinical data as well (Huang et al., 1997; Matsuo et al., 1997).

Work with ELT cell lines in vitro further supports the contention that leiomyomas have an enhanced sensitivity/responsiveness to steroid hormones. These cells retain estrogen and progesterone receptors and proliferate in response 

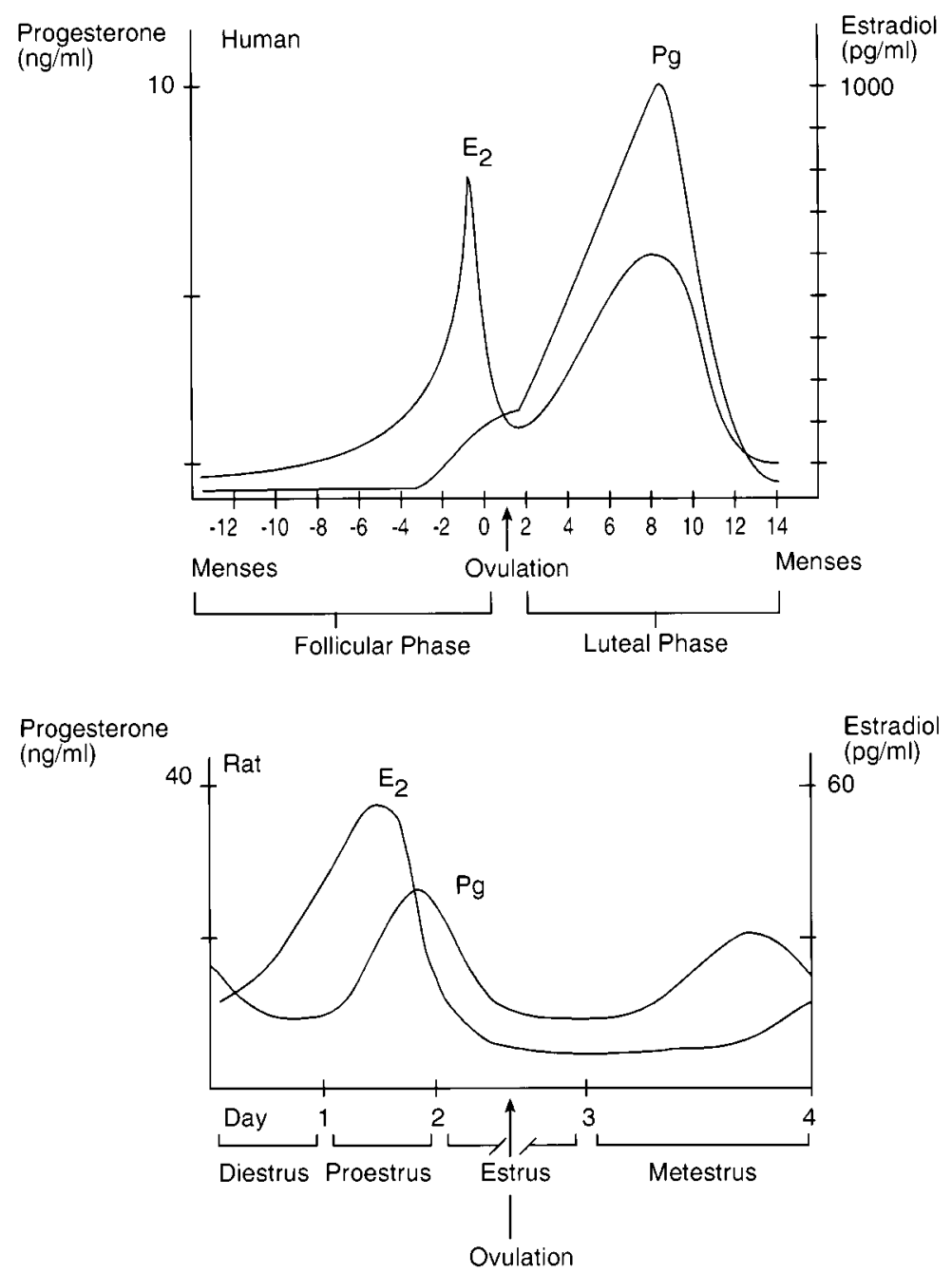

FIG. 2. Comparison of cycling hormone levels during the menstrual and estrus cycles. Species-specific differences occur in the cyclical levels of steroid hormones throughout the menstrual (human) and estrus (rodent) cycles. Estrogen exhibits a bimodal pattern during the menstrual cycle, whereas only a single peak in the level of this hormone occurs during the estrus cycle in rats. Progesterone levels also show differences between the two species, exhibiting a single peak during the menstrual cycle but exhibiting a bimodal pattern during the rat estrus cycle. [Data adapted from Speroff L, Vande Wiele RL 1971 Regulation of the human menstrual cycle. Am J Obstet Gynecol 109:234-247; and adapted with permission from Smith M, Freeman M, Neill J 1975 The control of progesterone secretion during the estrous cycle and early pseudopregnancy in the rat:prolactin, gonadotropin and steroid levels associated with rescue of the corpus luteum of pseudopregnancy. Endocrinology 96:219-226. Copyright The Endocrine Society.] 
to $10^{-6}$ to $10^{-10} \mathrm{M} 17-\beta$-estradiol (Howe et al., 1995b). This is fortuitous and contrasts with human myometrial and leiomyoma cells, which rapidly lose their receptors in tissue culture (Severino et al., 1996). In addition to responding to estrogen in vitro, leiomyoma cells also respond to this hormone in vivo. When ELT cells are injected subcutaneously into nude mice, they form tumors and grow as xenografts. With estrogen supplementation, mean tumor volume of these xenografts is increased two-fold (Howe et al., 1995b), again demonstrating the estrogen responsiveness of these tumor cells. Although hormone responsive, ELT cells do not require estrogen for cell growth, probably due to the insulin-like growth factor 1 (IGF-I) autocrine loop present in these cells (Howe et al., 1996). However, when deprived of growth factors via serum starvation, ELT cells will growth arrest and undergo apoptosis. Treatment of serum-starved cells with estrogen increases cell number. This rescue is mediated by enhanced cell proliferation rather than inhibition of apoptosis, which occurs at the same rate in the presence and absence of estrogen (Burroughs et al., 1997). Thus, estrogen appears to be a mitogen for leiomyomas that can modulate cell proliferation but has little effect on the apoptotic program of these tumors.

\section{Hormonal and Reproductive Factors That Modulate Tumor Development}

Several endogenous or environmental factors that modulate risk for developing uterine leiomyoma affirm the hormone responsive nature of this disease. Obesity and age at menarche have been linked to an increased risk for uterine leiomyoma, while cigarette smoking, use of oral contraceptives containing progesterone, and parity have been identified as protective factors (Ross et al., 1986; Parazzini et al., 1988,1992,1996a,b; Kjerulff et al., 1996, Marshall et al., 1997,1998a,b; Chiaffarino et al., 1999a,b). Obesity, particularly in peri- and postmenopausal women, increases levels of circulating estrogen through aromatization of fat stores, while early menarche increases overall exposure to circulating ovarian hormones. Cigarette smoking induces enzymes that can promote estrogen metabolism. The progesterone present in estrogen + progesterone oral contraceptives opposes the action of estrogen present in these formulations. In the case of pregnancy, the risk of uterine leiomyoma in parous women is approximately half that of nulliparous women. The risk of developing this disease decreases significantly with increased number of pregnancies (Ross et al., 1986; Parazzini et al., 1988,1996a,b). However, epidemiological data have been subject to interpretation as to whether pregnancy per se is protective or, as leiomyomas are a major cause of infertility, women that develop these tumors are less fertile and thus have lower pregnancy rates. Although the mechanism by which parity acts as a protective factor is not yet clear, additional experimental 
data obtained in the Eker rat model suggest that the hormonal milieu associated with pregnancy may help prevent tumor development (Table II).

Nulliparous, virgin female Eker rats develop leiomyomas with a frequency of $65 \%$. When these animals are bred with fertile males, a dramatic shift in tumor incidence and presentation is observed. As shown in Table II, in females allowed to have a single litter to confirm fertility, tumor incidence was $71 \%$ for gross and microscopic lesions combined, whereas in animals undergoing multiple rounds of pregnancy (average five litters/animal), tumor incidence was reduced to $\approx 10 \%$. This protective effect was particularly pronounced for tumors of the uterine cervix, the primary site of tumor development in fertile/nulliparous animals $(\approx 80 \%$ ), whereas less than $15 \%$ of the tumors arose in this location in animals undergoing multiple pregnancies (Walker et al., in press) (Figure 3).

Pregnancy has been shown to modulate the incidence of other types of hormone-dependent tumors, although the mechanisms of this protective effect appear to operate at different levels in different cell types. In breast cancer, early pregnancy is the most protective, suggesting an effect on the normal target cell population from which these tumors arise (Colditz, 1993; Hulka, 1996; Kelsey and Bernstein, 1996; Adami et al., 1998). Experimental animal studies have confirmed this hypothesis and suggest that differentiation of ductal epithelial

TABLE II

Impact of Hormonal and Reproductive Factors on Uterine Leiomyoma

\begin{tabular}{|c|c|c|c|c|}
\hline Condition & Ovariectomy & $\begin{array}{l}\text { SERM treatment } \\
\text { (antiestrogen) }\end{array}$ & $\begin{array}{l}\text { Targertin treatment } \\
\text { (RXR ligand, } \\
\text { antiestrogen) }\end{array}$ & Pregnancy \\
\hline $\begin{array}{l}\text { Expected tumor } \\
\text { incidence }\end{array}$ & $\begin{array}{l}\text { Gross }+ \text { micro } \\
23 / 34=68 \% \\
\text { (sham surgery) }\end{array}$ & $\begin{array}{l}\text { Gross }+ \text { micro } \\
26 / 31=84 \% \\
\text { (placebo) } 23 / 37 \\
=62 \% \text { (vehicle) }\end{array}$ & $\begin{array}{l}\text { Gross }=8 / 24 \\
\text { Micro }=1 / 24 \\
\text { (vehicle) }\end{array}$ & $\begin{array}{l}\text { Gross }+ \text { micro } \\
12 / 17=71 \% \\
\text { (single-litter } \\
\text { fertile females) }\end{array}$ \\
\hline $\begin{array}{l}\text { Observed tumor } \\
\text { incidence }\end{array}$ & $\begin{array}{l}\text { Gross }+ \text { micro } \\
1 / 31=3 \%\end{array}$ & $\begin{array}{l}\text { Gross }+ \text { micro } \\
10 / 29=35 \% \\
\text { (tamoxifen) } \\
11 / 30=37 \% \\
(\text { LY 326315) }\end{array}$ & $\begin{array}{l}\text { Gross }=4 / 38 \\
\text { Micro }=9 / 38\end{array}$ & $\begin{array}{l}\text { Gross }+ \text { micro } \\
\text { (in parous rats } \\
\text { having } 4-5 \\
\text { litters) } \\
6 / 58=10 \%\end{array}$ \\
\hline Modulation & $\begin{array}{l}95 \% \text { decrease in } \\
\text { tumor incidence } \\
(p \leq 0.001)\end{array}$ & $\begin{array}{l}40-60 \% \\
\text { decrease in } \\
\text { tumor incidence } \\
(\mathrm{p} \leq 0.05)\end{array}$ & $\begin{array}{l}65 \% \text { decrease in } \\
\text { macroscopic } \\
\text { lesions } \\
(p \leq 0.05)\end{array}$ & $\begin{array}{l}86 \% \text { decrease in } \\
\text { tumor incidence } \\
(p \leq 0.001)\end{array}$ \\
\hline Reference & $\begin{array}{l}\text { Walker et al., } \\
2000\end{array}$ & $\begin{array}{l}\text { Walker et al., } \\
2000\end{array}$ & $\begin{array}{l}\text { Gamage et al. } \\
2000\end{array}$ & $\begin{array}{l}\text { Walker et al., in } \\
\text { press }\end{array}$ \\
\hline
\end{tabular}



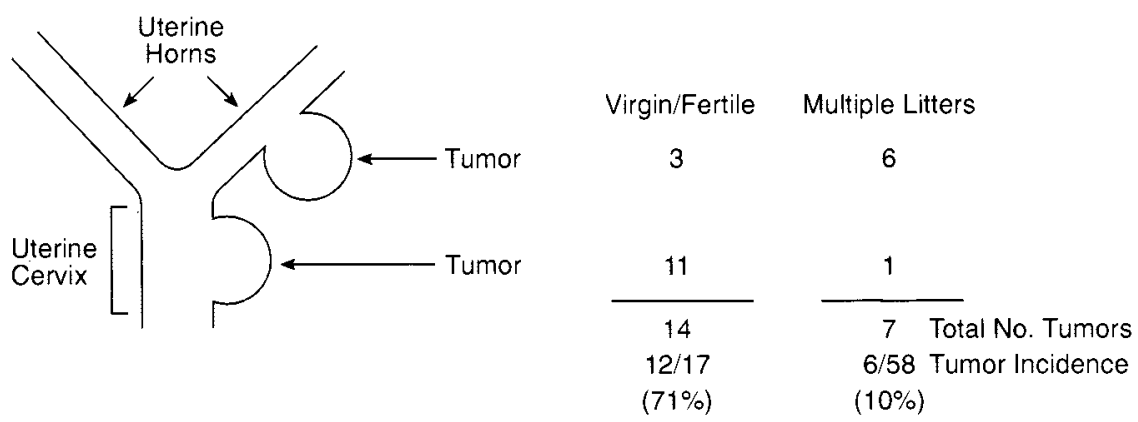

FIG. 3. Presentation of leiomyomas as a function of parity. In addition to reducing tumor incidence, pregnancy changes the spatial distribution of tumors. Virgin animals and those having a single litter (to confirm fertility) primarily develop tumors within the uterine cervix, whereas those undergoing multiple pregnancies develop tumors primarily on the uterine horns.

cells in the mammary gland mediated by the hormones of pregnancy contributes significantly to the protective effect of this condition (Abrams et al., 1998; Russo and Russo, 1998; Sivaraman et al., 1998; Guzman et al., 1999). In contrast, in the endometrium, time of last pregnancy appears to be a more important determinant. In women with only a single pregnancy, the most protection is afforded to women having a late rather than early pregnancy. This suggests that the protective effect is acting against the nascent neoplastic/preneoplastic cell population (Albrektsen et al., 1995; Hirose et al., 1996; Franchesschi, 1998; Lambe et al., 1999; Parslov et al., 2000). The fact that no protection against the development of uterine leiomyoma was afforded female Eker rats undergoing a single early pregnancy would suggest that the protective mechanisms of pregnancy in the myometrium are more similar to the endometrium (i.e., acting against nascent tumor cells) than the breast (protective differentiation).

Anderson and Barbieri first suggested an interesting hypothesis in which leiomyoma cells were described as resembling a myometrial cell of pregnancy rather than a typical myometrial cell under the influence of the menstrual cycle (Andersen et al., 1995). These similarities include increased levels of steroid hormone receptors, expression of IGF-I, and production of extracellular matrix proteins such as collagens type I and II. Furthermore, leiomyomas constitutively express high levels of connexin 43, the predominant connexin found in the myometrium during pregnancy (Andersen et al., 1993). Connexin 43 expression is negligible in myometrial cells during the normal menstrual cycle and early pregnancy; however, at term, connexin 43 becomes abundantly expressed under the influence of estrogen (Chow and Lye, 1994). This confirms that leiomyomas not only share the characteristics of myometrial cells during pregnancy but more specifically have the phenotype of these cells at parturition. At parturition, myometrial smooth muscle cells have a unique phenotype that differentiates 
them from myometrial cells at other stages of pregnancy. High levels of expression of a number of contraction-associated proteins (e.g., connexin 43, oxytocin receptors, cycloxygenase and its associated prostaglandins) are unique to the parturient myometrial cell. Leiomyoma cells share this phenotype but differ from the parturient myometrium in that they are neoplastic. Key biochemical and molecular differences must exist between a myometrial cell at parturition and a leiomyoma cell to account for this difference. An example of one such fundamental difference between myometrial cells and leiomyomas is their ability or inability, respectively, to undergo the biological program responsible for remodeling and involution of the uterus that occurs in a pregnant myometrial cell following parturition. In leiomyoma cells, this deficiency may be due to their hypersensitivity to steroid hormones, which may prevent them from triggering the normal dedifferentiation or apoptotic program of a parturient myometrial cell and returning to a nongravid, quiescent state (Cesen-Cummings et al., 2000).

Selective estrogen receptor modulators (SERMs) are a new class of synthetic compounds that bind to the estrogen receptor and exhibit tissue-specific agonist or antagonist activity (Jordan and Furr, 2001). Compounds such as tamoxifen and raloxifene are two prototypical SERMs currently in clinical use for prevention/ treatment of breast cancer and osteoporosis (Nayfield et al., 1991; Jordan, 1992; Fuchs-Young, 2001). Tamoxifen is a nonsteroidal triphenylethylene that is metabolized in vivo to several intermediates, the principal one being N-desmethyltamoxifen. Raloxifene is a benzothiophene derivative that binds to the estrogen receptor with nanomolar affinity and, like tamoxifen, acts as an estrogen agonist or antagonist, depending on cellular context. The tissue specificity observed for these compounds has been exploited to provide antagonism of estrogen action in the breast, while avoiding adverse side effects in other hormone-responsive tissues. Unfortunately, in the uterus, tamoxifen acts as an agonist in the endometrium and can promote the development of endometrial carcinoma (Hardell, 1988; Fornander et al., 1989; Kedar et al., 1994; Hulka, 1997). However, until recently, the effect of these or other SERMs on the myometrium and on leiomyomas had not been investigated. Preclinical data obtained from the Eker rat model now suggest that this class of compounds may be effective therapeutic agents for leiomyoma.

In culture, ELT cell lines proliferate in response to estrogen. Both basal and estrogen-induced cell proliferation are inhibited by 4-OH tamoxifen (a biologically active metabolite of tamoxifen) and raloxifene (Howe et al., 1995b,1996; Fuchs-Young et al., 1996). When these cells are grown as xenografts in nude mice, estrogen treatment increases tumor size, whereas tamoxifen treatment decreases tumor size and increases tumor latency (Howe et al., 1995b). Furthermore, in vivo studies in which Eker rats were treated with either tamoxifen or raloxifene for 2-4 months demonstrated that SERMs reduced tumor incidence by $\approx 50 \%$ and significantly reduced the size of the remaining tumors (Walker $e t$ 
al., 2000) (Table II). Importantly, sectioning of uteri and examination of microscopic lesions in treated rats confirmed a reduction in the absolute number of persistent lesions. This contrasts with the clinical experience with GnRH agonists, which primarily reduce tumor size but do not decrease tumor cellularity (Cohen et al., 1994). These preclinical data in the Eker rat suggest that, in contrast to GnRH agonists, SERMs such as tamoxifen and raloxifene, which both protect the bone and cardiovascular system and ablate leiomyomas, may have efficacy as medicinal therapeutic agents for leiomyoma. In support of the potential efficacy of SERMs, raloxifene recently has been reported to shrink leiomyoma volume in postmenopausal women (Palomba et al., 2001).

An interesting aspect of the preclinical studies with SERMs was the finding that while tumors from treated animals were significantly smaller and had a reduced mitotic index, there was no change in the apoptotic indices of the treated tumors relative to vehicle-treated controls (Walker et al., 2000). SERMs acting as anti-estrogens in the myometrium and leiomyomas were able to inhibit cell proliferation but were ineffective at inducing apoptosis. These in vivo data are consistent with the description of leiomyoma cells as having an apoptotic defect that is refractory to modulation by estrogen. However, in another preclinical study, the retinoid X receptor (RXR) ligand targretin (LGD 1069) was shown to be effective at inducing apoptosis in these cells (Table II) (Gamage et al., 2000). Targretin previously has been demonstrated to act as an estrogen antagonist and to have efficacy as a chemopreventive agent for hormone-dependent mammary cancer (Gottardis et al., 1996; Fitzgerald et al., 1997). Treatment of tumorbearing Eker rats for 4 months with targretin decreased the number of grossly observable tumors and significantly increased tumor apoptotic indices (Gamage et al., 2000). These data suggest that, while refractory to the influence of traditional anti-estrogens, the apoptotic program of leiomyomas may be modulated via other signaling cascades, such as that induced via RXRs.

\section{Potential Impact of Environmental Estrogens}

Xenoestrogens with endocrine-disrupting activity have been associated with the dysregulation of reproductive function and promotion of malignancies in experimental animals and human populations. With the recognition of the ubiquitous presence of many of these xenoestrogens in our environment, the high incidence of uterine leiomyomas in women has called into question the potential influence of xenoestrogens in the pathogenesis of these tumors. Using ELT cell lines, several in vitro assays have been developed to assess the estrogen-like agonist activity of potential endocrine disruptors on leiomyoma cells. These assays demonstrate that compounds from three major classes of xenoestrogens can mimic the effect of estrogen on leiomyoma cells and act as ER agonists: phytoestrogens, organochlorine pesticides, and pharmacologic agents. These 
compounds can stimulate proliferation of ELT cells in culture and transactivate expression of an ERE-reporter construct and an endogenous estrogen-responsive gene, the progesterone receptor, in leiomyoma cells (Hunter et al., 1999; Hodges et al., 2000). Diethylstilbestrol, the phytoestrogens coumesterol, genistein, and narigenin, and the organochlorine pesticides endosulfan, kepone, and HPTE (the active metabolite of metoxychlor) are all able to stimulate cell proliferation in estrogen-deficient medium. Additionally, the organochlorine pesticides methoxychlor, dieldrin, and toxaphene, while unable to stimulate cell proliferation, were able to act as agonists at the molecular level to transactivate the ER to induce expression of both ERE reporter genes and transcription of the PR. Interestingly, agonist activity by these compounds in leiomyoma cells requires activation of both AF1 and AF2 functions of the ER. Compounds that activate AF1 but fail to activate $\mathrm{AF} 2,4-\mathrm{OH}$ tamoxifen, and two raloxifene analogs act as antagonists in these cells (Hunter et al., 1999).

Significantly elevated levels of organochlorine pesticides previously have been detected in tumors and blood samples of women with leiomyoma (Saxena et al., 1987). These studies suggest a possible link between organochlorine pesticide exposure and the development of uterine leiomyomas. Organochlorine pesticides tend to bioaccumulate in fat stores and to be released during lactation and times of stress such as fasting. Under these conditions, exposure levels may be substantially higher within the body than those originally encountered in the environment. Furthermore, windows of susceptibility may exist at times when circulating estrogen levels are low. Exposure to even relatively low levels of xenoestrogens during windows of susceptibility, such as during the neonatal period, could produce deleterious effects on the reproductive system and potentially contribute to the development of leiomyomas. Several studies have implicated exposure to organochlorine pesticides such as dieldrin with an increased incidence of breast cancer (Wolff et al., 1993; Hoyer et al., 1998), although these data are controversial and recently have been called into question (Hunter et al., 1999).

\section{Summary}

It is clear that hormonal milieu has a tremendous impact on the growth and development of uterine leiomyoma. Using experimental animal models such as the Eker rat, it is possible to dissect these hormonal factors and determine their influence on specific aspects of tumor etiology and treatment in ways that are difficult or impossible to approach in humans. As shown in Figure 4, using the Eker rat model, it has been possible to clearly demonstrate that the development of leiomyoma is dependent on steroid hormones and this process can be modulated by several hormonal and reproductive factors. Tumor development is promoted by steroid hormones, and possibly by xenoestrogens, while other 


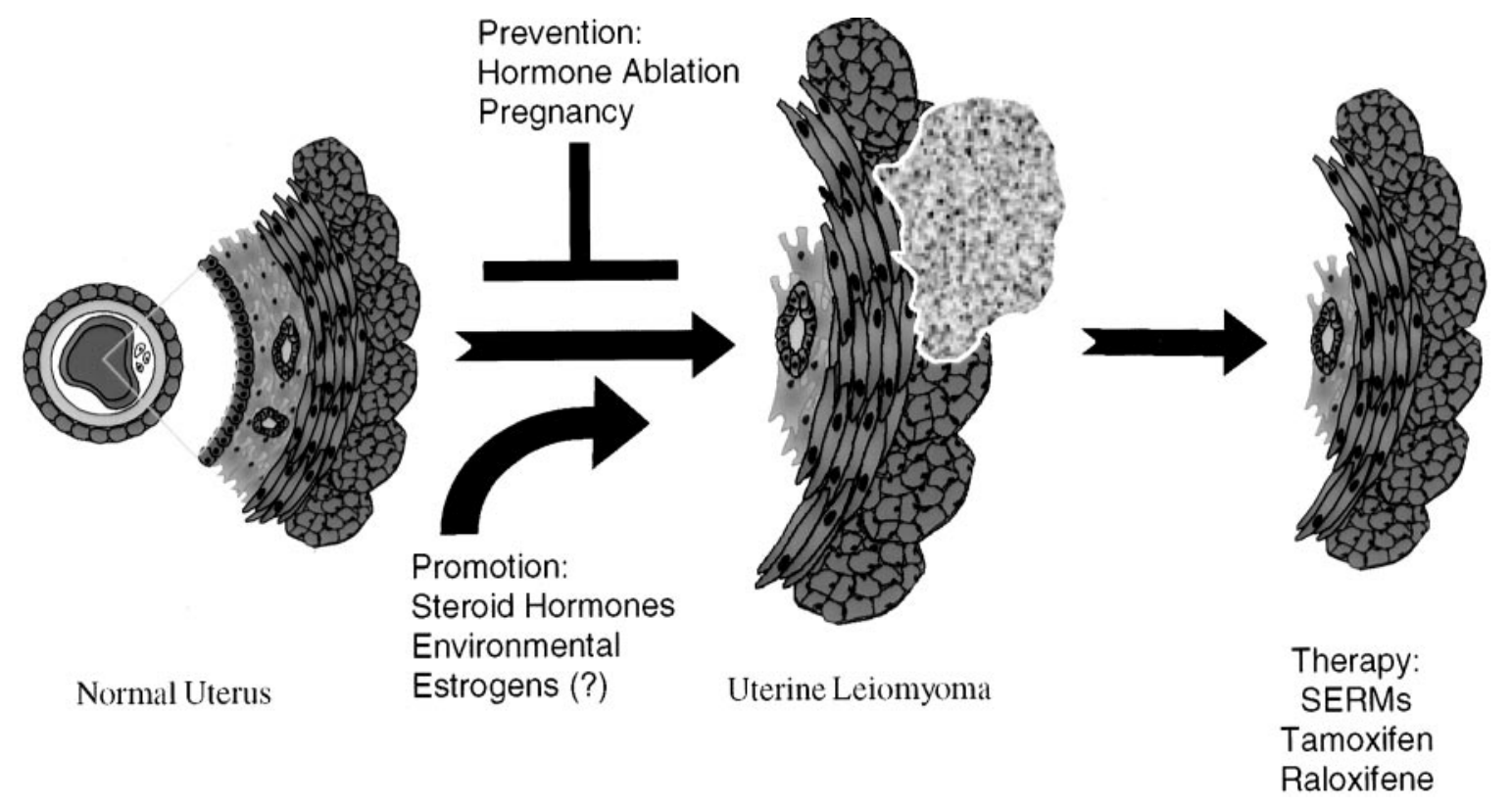

FIG. 4. Hormonal and reproductive factors that impact uterine leiomyomas. Uterine leiomyomas are hormone-dependent tumors and the development of this disease can be promoted by estrogens and inhibited by hormone ablation and pregnancy. SERMs have been demonstrated in preclinical studies to be effective at inhibiting tumor growth and offer promise as new therapeutic agents for this disease. 
alterations in a women's hormonal milieu, such as that which occurs during pregnancy, may prevent the development of these tumors. Because leiomyomas retain their hormone-responsive phenotype, they are amenable to hormonal therapy. Traditional adjuvant therapy with GnRH agonists has been demonstrated to reduce tumor burden and symptoms but induces serious side effects associated with the generalized hypoestrogenic milieu these drugs induce. Preclinical studies in the Eker rat model indicate that SERMs, which act as estrogen antagonists in leiomyomas while acting as estrogen agonists in the bone and cardiovascular system, hold promise as new candidate therapeutic agents for this disease.

\section{ACKNOWLEDGMENTS}

These studies were sponsored in part by funding from the National Institutes of Health grant ES08263 and CA72253 (C.L.W.), ES07784 and CA16672. We thank M. Gardiner for assistance with manuscript preparation and D. Hunter for comments and critical review of the manuscript.

\section{REFERENCES}

Abrams TJ, Guzman RC, Swanson SM, Thordarson G, Talamantes F, Nandi S 1998 Changes in the parous rat mammary gland environment are involved in parity-associated protection against mammary carcinogenesis. Anticancer Res 18:4115-4121

Adami HO, Signorello LB, Trichopoulos D 1998 Towards an understanding of breast cancer etiology. Semin Cancer Biol 8:255-262

Adamson GD 1992 Treatment of uterine fibroids: current findings with gonadotropin- releasing hormone agonists. Am J Obstet Gynecol 166:746-751

Albrektsen G, Heuch I, Tretli S, Kvale G 1995 Is the risk of cancer of the corpus uteri reduced by a recent pregnancy? A prospective study of 765,756 Norwegian women. Intl J Cancer 61:485-490

Andersen J, Grine E, Eng CL, Zhao K, Barbieri RL, Chumas JC, Brink PR 1993 Expression of connexin-43 in human myometrium and leiomyoma. Am J Obstet Gynecol 169:1266-1276

Andersen J, DyReyes VM, Barbieri RL, Coachman DM, Miksicek RJ 1995 Leiomyoma primary cultures have elevated transcriptional response to estrogen compared with autologous myometrial cultures. J Soc Gynecol Invest 2:542-551

Andreyko JL, Marshall LA, Dumesic DA, Jaffee RB 1987 Therapeutic uses of gonadotropinreleasing hormone analogs. Obstet Gynecol Surv 42:1-21

Brandon DD, Bethea CL, Strawn EY, Novy MJ, Burry KA, Harrington MS, Erickson TE, Warner C, Keenan EJ, Clinton GM 1993 Progesterone receptor messenger ribonucleic acid and protein are overexpressed in human uterine leiomyomas. Am J Obstet Gynecol 169: $78-85$

Brandon DD, Erickson TE, Keenan EJ, Strawn EY, Novy MJ, Burry KA, Warner C, Clinton GM 1995 Estrogen receptor gene expression in human uterine leiomyomata. J Clin Endocrinol Metab 80:1876-1881

Burroughs KD, Kiguchi K, Howe SR, Fuchs-Young R, Trono D, Barrett JC, Walker C 1997 Regulation of apoptosis in uterine leiomyomata. Endocrinology 138:3056-3064

Burroughs KD, Fuchs-Young R, Davis B, Walker CL 2000 Altered hormonal responsiveness of proliferation and apoptosis during myometrial maturation and the development of uterine leiomyomas in the rat. Biol Reprod 63:1322-1330 
Buttram V, Reiter R 1981 Uterine leiomyomata: etiology, symptomatology, and management. Fertil Steril 36:433-445

Cesen-Cummings K, Copland JA, Barrett JC, Walker CL, Davis BJ 2000 Pregnancy, parturition, and prostaglandins: defining uterine leiomyomas. Envir Health Perspect 108(suppl 5):817820

Chiaffarino F, Parazzini F, La Vecchia C, Chatenoud L, Di Cintio E, Marsico S 1999a Diet and uterine myomas. Obstet Gynecol 94:395-398

Chiaffarino F, Parazzini F, La Vecchia C, Marsico S, Surace M, Ricci E 1999b Use of oral contraceptives and uterine fibroids: results from a case-control study. Br J Obstet Gynaecol 106:857-860

Chow L, Lye SJ 1994 Expression of the gap junction protein connexin-43 is increased in the human myometrium toward term and with the onset of labor. Am J Obstet Gynecol 170:788-795

Cohen D, Mazur MT, Jozefczyk MA, Badawy SZA 1994 Hyalinization and cellular changes in uterine leiomyomata after gonadotropin releasing hormone agonist therapy. J Reprod Med 194:337-380

Colditz GA 1993 Epidemiology of breast cancer. Findings from the nurses' health study. Cancer 71:1480-1489

Cramer D 1992 Epidemiology of myomas. Semin Repro Endocrinol 10:320-324

Cramer S, Patel B 1990 The frequency of uterine leiomyomas. Am J Clin Pathol 94:435-438

Dawood MY, Lewis V, Ramos J 1989 Cortical and trabecular bone mineral content in women with endometriosis: effect of gonadotropin-releasing hormone agonist and danazol. Fertil Steril 52:21-26

Englund K, Blanck A, Gustavsson I, Lundkvist U, Sjoblom P, Norgren A, Lindblom B 1998 Sex steroid receptors in human myometrium and fibroids: changes during the menstrual cycle and gonadotropin-releasing hormone treatment. J Clin Endocrinol Metab 83:4092-4096

Everitt JI, Wolf DC, Howe SR, Goldsworthy TL, Walker C 1995 Rodent model of reproductive tract leiomyomata. Clinical and pathological features. Am J Pathol 146:1556-1567

Fitzgerald P, Teng M, Chandraratna RA, Heyman RA, Allegretto EA 1997 Retinoic acid receptor alpha expression correlates with retinoid-induced growth inhibition of human breast cancer cells regardless of estrogen receptor status. Cancer Res 57:2642-2650

Fornander T, Cedermark B, Mattsson A, Skoog L, Theve T, Askergren J, Rutqvist LE, Glas U, Silfversward C, Somell A, Wilking N, Hjalmar M-L 1989 Adjuvant tamoxifen in early breast cancer: occurrence of new primary cancers. Lancet 1:117-120

Franchesschi S 1998 Role of reproductive factors on the risk of endometrial cancer. Int J Cancer 76:784-786

Friedman AJ, Lobel SM, Rein MS, Barbieri RL 1990 Efficacy and safety considerations in women with uterine leiomyomas treated with gonadotropin-releasing hormone agonists: the estrogen threshold hypothesis. Am J Obstet Gynecol 163:1114-1119

Fuchs-Young R 2002 Preclinical studies of raloxifene and related compounds. In Jordan VC, Furr W, eds. Antiestrogens and Antiandrogens. Totowa, NJ: Humana Press, in press

Fuchs-Young R, Howe S, Hale L, Miles R, Walker C 1996 Inhibition of estrogen-stimulated growth of uterine leiomyomas by selective estrogen receptor modulators. Mol Carcinog 17:151-159

Gamage SD, Bischoff ED, Burroughs KD, Lamph WW, Gottardis MM, Walker CL, FuchsYoung R 2000 Efficacy of LGD1069 (Targretin), a retinoid X receptor-selective ligand, for treatment of uterine leiomyoma. J Pharmacol Exp Ther 295:677-681

Gottardis MM, Bischoff ED, Shirley MA, Wagoner MA, Lamph WW, Heyman RA 1996 Chemoprevention of mammary carcinoma by LGD1069 (Targretin): an RXR-selective ligand. Cancer Res 56:5566-5570 
Guzman RC, Yang J, Rajkumar L, Thordarson G, Chen X, Nandi S 1999 Hormonal prevention of breast cancer: mimicking the protective effect of pregnancy. Proc Natl Acad Sci USA 96:2520-2525

Hardell L 1988 Tamoxifen as risk factor for carcinoma of corpus uteri. Lancet 563(2):563

Hirose K, Tajima K, Hamajima N, Takezaki T, Inoue M, Kuroishi T, Kuzuya K, Nakamura S, Tokudome S 1996 Subsite (cervix/endometrium)-specific risk and protective factors in uterus cancer. Jpn J Cancer Res 87:1001-1009

Hodges LC, Bergerson JS, Hunter DS, Walker CL 2000 Estrogenic effects of organochlorine pesticides on uterine leiomyoma cells in vitro. Toxicol Sci 54:355-364

Howe S, Gottardis M, Everitt J, Goldsworthy T, Wolf D, Walker C 1995a Rodent model of reproductive tract leiomyomata: establishment and characterization of tumor-derived cell lines. Am J Pathol 146:1568-1579

Howe SR, Gottardis MM, Everitt JI, Walker C 1995b Estrogen stimulation and tamoxifen inhibition of leiomyoma cell growth in vitro and in vivo. Endocrinology 136:4996-5003

Howe SR, Pass HI, Ethier SP, Matthews WJ, Walker C 1996 Presence of an insulin-like growth factor I autocrine loop predicts uterine fibroid responsiveness to tamoxifen. Cancer Res 56:4049-4055

Hoyer AP, Grandjean P, Jorgensen T, Brock JW, Hartvig HB 1998 Organochlorine exposure and risk of breast cancer. Lancet 352:1816-1820

Huang SC, Chou CY, Lin YS, Tsai YC, Hsu KF, Liu CH, Huang KE 1997 Enhanced deoxyribonucleic acid damage and repair but unchanged apoptosis in uterine leiomyomas treated with gonadotropin-releasing hormone agonist. Am J Obstet Gynecol 177:417-424

Hulka BS 1996 Epidemiology of susceptibility to breast cancer. Prog Clin Biol Res 395:159-174

Hulka BS 1997 Epidemiologic analysis of breast and gynecologic cancers. Prog Clin Biol Res 396:17-29

Hunter DS, Hodges LC, Vonier PM, Fuchs-Young R, Gottardis MM, Walker CL 1999 Estrogen receptor activation via activation function 2 predicts agonism of xenoestrogens in normal and neoplastic cells of the uterine myometrium. Cancer Res 59:3090-3099

Jordan VC 1992 The role of tamoxifen in the treatment and prevention of breast cancer. Curr Prob Cancer 16:129-176

Jordan VC, Furr W, eds. 2002 Antiestrogens and Antiandrogens. Totowa, NJ: Humana Press

Kawaguchi K, Fuji S, Konishi I, Nanbu Y, Nonogaki H, Mori T 1989 Mitotic activity in uterine leiomyomas during the menstrual cycle. Am J Obstet Gynecol 160:637-641

Kedar RP, Bourne TH, Powles TJ, Collins WP, Ashley SE, Cosgrove DO, Campbell S 1994 Effects of tamoxifen on uterus and ovaries of postmenopausal women in a randomised breast cancer prevention trial. Lancet 343:1318-1321

Kelsey JL, Bernstein L 1996 Epidemiology and prevention of breast cancer. Annu Rev Public Health 17:47-67

Kjerulff KH, Langenberg P, Seidman JD, Stolley PD, Guzinski GM 1996 Uterine leiomyomas. Racial differences in severity, symptoms and age at diagnosis. J Reprod Med 41:483-490

Kobayashi T, Hirayama Y, Kobayashi E, Kubo Y, Hino O 1995 A germline insertion in the tuberous sclerosis (Tsc2) gene gives rise to the Eker rat model of dominantly inherited cancer. Nature Genet 9:70-74

Lambe M, Wuu J, Weiderpass E, Hsieh CC 1999 Childbearing at older age and endometrial cancer risk (Sweden). Cancer Causes Control 10:43-49

Marshall LM, Spiegelman D, Barbieri RL, Goldman MB, Manson JE, Colditz GA, Willett WC, Hunter DJ 1997 Variation in the incidence of uterine leiomyoma among premenopausal women by age and race. Obstet Gynecol 90:967-973 
Marshall LM, Spiegelman D, Goldman MB, Manson JE, Colditz GA, Barbieri RL, Stampfer MJ, Hunter DJ 1998a A prospective study of reproductive factors and oral contraceptive use in relation to the risk of uterine leiomyomata. Fertil Steril 70:432-439

Marshall LM, Spiegelman D, Manson JE, Goldman MB, Barbieri RL, Stampfer MJ, Willett WC, Hunter DJ 1998b Risk of uterine leiomyomata among premenopausal women in relation to body size and cigarette smoking. Epidemiology 9:511-517

Matsuo H, Maruo T, Samoto T 1997 Increased expression of Bc1-2 protein in human uterine leiomyoma and its upregulation by progesterone. J Clin Endocrinol Metab 82:293-299

Nayfield SG, Karp JE, Ford LG, Dorr A, Kramer BS 1991 Potential role of tamoxifen in prevention of breast cancer. J Natl Cancer Inst 83:1450-1459

Nisolle M, Gillerot S, Casanas-Roux F, Squifflet J, Berliere M, Donnez J 1999 Immunohistochemical study of the proliferation index, oestrogen receptors and progesterone receptors A and $\mathrm{B}$ in leiomyomata and normal myometrium during the menstrual cycle and under gonadotrophin-releasing hormone agonist therapy. Hum Reprod 14:2844-2850

Palomba S, Sammartino A, Di Carlo C, Affinito P, Zullo F, Nappi C 2001 Effects of raloxifene treatment on uterine leiomyomas in postmenopausal women. Fertil Steril 76:38-43

Parazzini F, Negri E, La Vecchia C, Fedele L, Rabaiotti M, Luchini L 1992 Oral contraceptive use and risk of uterine fibroids. Obstet Gynecol 79:430-433

Parazzini F, Negri E, La Vecchia C, Chatenoud L, Ricci E, Guarnerio P 1996a Reproductive factors and risk of uterine fibroids. Epidemiology 7:440-442

Parazzini F, Negri E, La Vecchia C, Rabaiotti M, Luchini L, Villa A, Fedele L 1996b Uterine myomas and smoking. Results from an Italian study. J Reprod Med 41:316-320

Parazzini F, La Vecchia C, Negri E, Cecchetti G, Fedele L 1988 Epidemiologic characteristics of women with uterine fibroids: a case-control study. Obstet Gynecol 72:853-857

Parslov M, Lidegaard O, Klintorp S, Pedersen B, Jonsson L, Eriksen PS, Ottesen B 2000 Risk factors among young women with endometrial cancer: a Danish case-control study. Am J Obstet Gynecol 182:23-29

Rein M, Nowak R 1992 Biology of uterine myomas and myometrium in vitro. Semin Reprod Endocrinol 10:310-319

Ross RK, Pike MC, Vessey MP, Bull D, Yeates D, Casagrande JT 1986 Risk factors for uterine fibroids: reduced risk associated with oral contraceptives. Br Med J (Clin Res Ed) 293: $359-362$

Rossi G, Diamond MP 1992 Myomas, reproductive function, and pregnancy. Semin Reprod Endocrinol 10:332-338

Russo IH, Russo J 1998 Role of hormones in mammary cancer initiation and progression. J Mammary Gland Biol Neoplasia 3:49-61

Saxena SP, Khare C, Farooq A, Murugesan K, Buckshee K, Chandra J 1987 DDT and its metabolites in leiomyomatous and normal human uterine tissue. Arch Toxicol 59:453-455

Severino MF, Murray MJ, Brandon DD, Clinton GM, Burry KA, Novy MJ 1996 Rapid loss of oestrogen and progesterone receptors in human leiomyoma and myometrial explant cultures. Mol Hum Reprod 2:823-828

Sivaraman L, Stephens LC, Markaverich BM, Clark JA, Krnacik S, Conneely OM, O’Malley BW, Medina D 1998 Hormone-induced refractoriness to mammary carcinogenesis in Wistar-Furth rats. Carcinogenesis 19:1573-1581

Smith M, Freeman M, Neill J 1975 The control of progesterone secretion during the estrous cycle and early pseudopregnancy in the rat: prolactin, gonadotropin and steroid levels associated with rescue of the corpus luteum of pseudopregnancy. Endocrinology 96:219-226

Speroff L, Vande Wiele RL 1971 Regulation of the human menstrual cycle. Am J Obstet Gynecol 109:234-247 
Strobelt N, Ghidini A, Cavallone M, Pensabene I, Ceruti P, Vergani P 1994 Natural history of uterine leiomyomas in pregnancy. J Ultrasound Med 13:399-401

Viville B, Charnock-Jones DS, Sharkey AM, Wetzka B, Smith SK 1997 Distribution of the A and $\mathrm{B}$ forms of the progesterone receptor messenger ribonucleic acid and protein in uterine leiomyomata and adjacent myometrium. Hum Reprod 12:815-822

Walker CL, Burroughs KD, Davis B, Sowell K, Everitt JI, Fuchs-Young R 2000 Preclinical evidence for therapeutic efficacy of selective estrogen receptor modulators for uterine leiomyoma. J Soc Gynecol Investig 7:249-256

Walker CL, Cesen-Cummings K, Houle C, Baird D, Barrett JC, Davis B 2002 Protective effect of pregnancy for development of uterine leiomyoma. Carcinogenesis, in press

Wolff MS, Toniolo PG, Lee EW, Rivera M, Dubin N 1993 Blood levels of organochlorine residues and risk of breast cancer. J Natl Cancer Inst 85:648-652

Wu G, Somlo S 2000 Molecular genetics and mechanism of autosomal dominant polycystic kidney disease. Mol Genet Metab 69:1-15

Yeung RS, Xiao GH, Jin F, Lee WC, Testa JR, Knudson AG 1994 Predisposition to renal carcinoma in the Eker rat is determined by germ-line mutation of the tuberous sclerosis 2 (TSC2) gene. Proc Natl Acad Sci USA 91:11413-11416

Yeung RS, Xiao GH, Everitt JI, Jin F, Walker CL 1995 Allelic loss at the tuberous sclerosis 2 locus in spontaneous tumors in the Eker rat. Mol Carcinog 14:28-36 